\title{
Multistage A-O Activated Sludge Process for Paraformaldehyde Wastewater Treatment and Microbial Community Structure Analysis
}

\author{
Danyang Zheng, ${ }^{1}$ Yujiao Sun, ${ }^{1}$ Huijuan $\mathrm{Li}^{2}{ }^{2}$ Sidan Lu, ${ }^{1}$ Mingjun Shan, ${ }^{1}$ and Shangwei Xu ${ }^{1}$ \\ ${ }^{1}$ College of Water Science, Beijing Normal University, Beijing 100875, China \\ ${ }^{2}$ Beijing Water Business Doctor CO. Ltd., Beijing 100875, China \\ Correspondence should be addressed to Yujiao Sun; sun201405@163.com
}

Received 21 July 2016; Accepted 9 October 2016

Academic Editor: Reyna Natividad

Copyright ( 92016 Danyang Zheng et al. This is an open access article distributed under the Creative Commons Attribution License, which permits unrestricted use, distribution, and reproduction in any medium, provided the original work is properly cited.

In recent years, the effect of formaldehyde on microorganisms and body had become a global public health issue. The multistage combination of anaerobic and aerobic process was adopted to treat paraformaldehyde wastewater. Microbial community structure in different reaction stages was analyzed through high-throughput sequencing. Results showed that multistage A-O activated sludge process positively influenced polyformaldehyde wastewater. The removal rates of formaldehyde were basically stable at more than $99 \%$ and those of COD were about $89 \%$. Analysis of the microbial diversity index indicated that the microbial diversity of the reactor was high, and the treatment effect was good. Moreover, microbial community had certain similarity in the same system. Microbial communities in different units also showed typical representative characteristics affected by working conditions and influent concentrations. Proteobacteria, Firmicutes, and Bacteroidetes were the dominant fungal genera in the phylum level of community composition. As to family and genus levels, Peptostreptococcaceae was distributed at various stages and the dominant in this system. This bacterium also played an important role in organic matter removal, particularly decomposition of the acidified middle metabolites. In addition, Rhodobacteraceae and Rhodocyclaceae were the formaldehyde-degrading bacteria found in the reactor.

\section{Introduction}

Formaldehyde is a basic chemical raw material widely used in plastics, chemical, leather, resin, and other production processes. Formaldehyde is soluble in water; the emissions of aqueous solution of this compound can bring serious pollution to water and even kill water creatures. Meanwhile, formaldehyde can produce irritating effect on human body, damage the immune system, and cause cancer. Therefore, China has launched a series of emission regulatory controls for formaldehyde wastewater. For example, the secondary emission standard of formaldehyde must not exceed $2 \mathrm{mg} / \mathrm{L}$ in the standard of integrated wastewater discharge, and the formaldehyde content of centralized surface water for domestic and drinking water must not exceed $0.9 \mathrm{mg} / \mathrm{L}$ in the standard of surface water environment quality $[1,2]$. The large source and quantity of formaldehyde wastewater cause certain difficulties to wastewater treatment. But considering economic or reality reasons, we cannot ban the application of formaldehyde on the whole. Therefore, we need to treat formaldehyde wastewater from industrial production properly. Physical, chemical, and biological methods are mainly used for wastewater treatment. Physical methods include steam blow-off and adsorption. Blowing can be used as a pretreatment process. The effect of formaldehyde wastewater treatment on adsorption is satisfactory but presents limitations in adsorbent recycling. Chemical methods, including advanced oxidation and condensation/precipitation, are expensive. Biological methods are characterized by low cost, simple operation, and low pollution. Most microbes can use formaldehyde as carbon source and degrade wastewater [3]. Hidalgo [4] used Rhodococcus erythropolis UPV1 in formaldehyde wastewater treatment. Both continuous dosing and intermittent dosing can form stable colony. The formaldehyde and chemical oxygen demand (COD) removal rates are $90 \%$ and 56\%, respectively. Wang et al. [5] used 


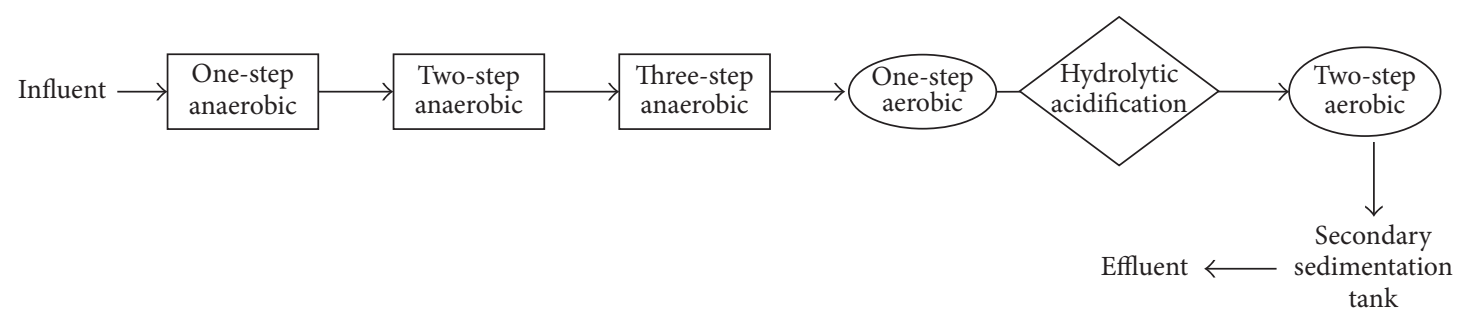

Figure 1: Process flow diagram in the field.

TABLE 1: Flooding water quality and sludge properties in the field.

\begin{tabular}{lcccccccc}
\hline Index & $\mathrm{HCHO}(\mathrm{mg} / \mathrm{L})$ & $\mathrm{COD}(\mathrm{mg} / \mathrm{L})$ & $\mathrm{pH}$ & $\mathrm{MLSS}(\mathrm{mg} / \mathrm{L})$ & $\mathrm{DO}(\mathrm{mg} / \mathrm{L})$ & $\mathrm{SV}_{30}(\%)$ & $\mathrm{SVI}(\mathrm{mL} / \mathrm{g})$ & $\mathrm{SS}(\mathrm{mg} / \mathrm{L})$ \\
\hline Content & $650 \sim 1200$ & $4000 \sim 5800$ & $3.55 \sim 3.80$ & $5900 \sim 15000$ & $3.40 \sim 4.75$ & $90 \sim 98$ & $124 \sim 683$ & $200 \sim 440$ \\
\hline
\end{tabular}

activated sludge process in the treatment of formaldehyde wastewater. The results showed that the initial concentration of formaldehyde is $400 \mathrm{mg} / \mathrm{L}$ and the sludge concentration is $4 \mathrm{~g} / \mathrm{L}$ after $10 \mathrm{~h}$; in addition, the removal rates of formaldehyde and COD reach more than $99 \%$ and $83 \%$, respectively. Methylobacillus flagellatus [6], Pseudomonas putida [7], Ralstonia eutropha [8], and Candida maltose [9] have been reported in formaldehyde degradation. Nevertheless, the degradation effect of these strains shows differences. Most of the strains can only degrade low formaldehyde concentration. Suitable degradation strains should still be determined for highconcentration formaldehyde produced in industrial process. The present study adopted multistage A-O activated sludge process in the treatment of polyformaldehyde wastewater; microbes in the sludge can use formaldehyde as carbon source and degrade wastewater. The process was complex, and the hydraulic retention time was short. This in-depth process can be reproducible in view of high concentration and complex wastewater. We used high-throughput sequencing technology to analyze the change in microbial community, ecological information of colony, and degradation function relationship in different reaction steps in depth. We hoped that our work can provide certain technical and theoretical support for the actual project. Therefore, we can treat formaldehyde wastewater better and reduce its harm to environment and human body.

\section{Materials and Methods}

2.1. Overview of the Reactor. This study was based on the polyformaldehyde wastewater treatment in the production process in a chemical plant. The experiment process is as follows: raw water $\rightarrow$ iron and carbon microelectrolysis $\rightarrow$ one-step anaerobic (A1) $\rightarrow$ two-step anaerobic (A2) $\rightarrow$ threestep anaerobic $(\mathrm{A} 3) \rightarrow$ one-step aerobic $(\mathrm{O} 1) \rightarrow$ hydrolytic acidification $\rightarrow$ two-step aerobic (O2). The process flow diagram and the flooding water quality and sludge properties in the field are shown in Figure 1 and Table 1.

2.2. Sample Collection. The collection date was June 8, 2015, and the sludge samples were obtained from A1, A2, A3, O1, hydrolysis acidification, and $\mathrm{O} 2$. We collected the samples in
TABLE 2: Sludge sample number information in the reactor.

\begin{tabular}{lc}
\hline Sample number & Sampling stage \\
\hline A1D & One-step anaerobic \\
A2D & Two-step anaerobic \\
A3D & Three-step anaerobic \\
O1D & One-step aerobic \\
BD & Hydrolytic acidification \\
O2D & Two-step aerobic \\
\hline
\end{tabular}

TABLE 3: Testing index and method of activated sludge.

\begin{tabular}{lc}
\hline Testing index & Testing method \\
\hline SS & Dry weight \\
SV $_{30}$ & Sedimentation method \\
SVI & Settlement of weighing \\
MLSS & Weight method \\
\hline
\end{tabular}

the reactor when it was starting. The sludge sample number information is shown in Table 2.

2.3. Chemical Analysis. Conventional water quality indicators, such as $\mathrm{pH}$, temperature, and $\mathrm{COD}$, were analyzed using the national standard method [10]. The dissolved oxygen (DO) and formaldehyde concentration were analyzed using the DO instrument. Table 3 shows the testing index and method of activated sludge.

2.4. DNA Extraction and High-Throughput Sequencing. DNA was extracted via phenol-chloroform extraction and was purified by purification kit (TIANquick Midi Purification Kit, Tiangen). DNA samples were detected of fragment length through agarose gel electrophoresis detection after purification. The concentration and purity were determined by Nanodrop. PCR (Polymerase Chain Reaction) amplification was carried out, and the amplification products were used for DNA sequencing [11]. The library of sequencing DNA was constructed by TruSeq kit (Illumina, USA) and was determined by Illumina Miseq2500 high-throughput sequencing machine for sequencing. 


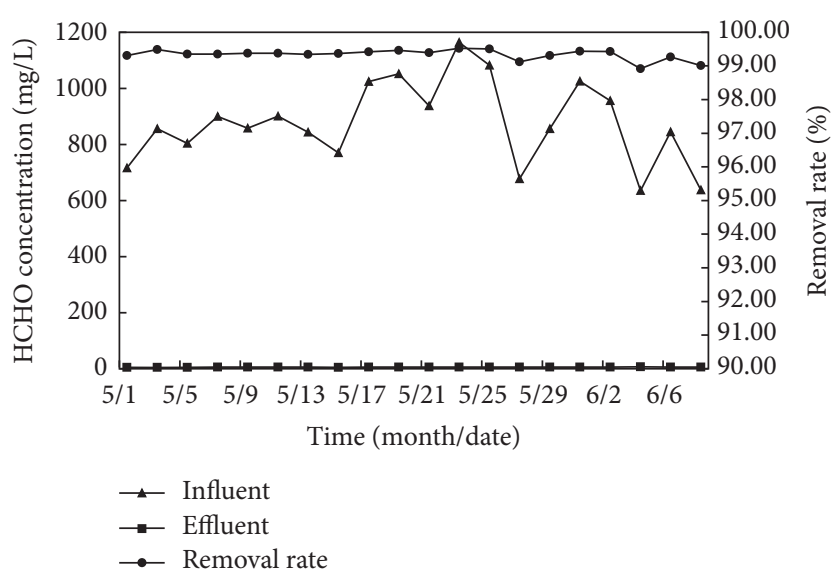

FigURE 2: Formaldehyde removal from the reactor.

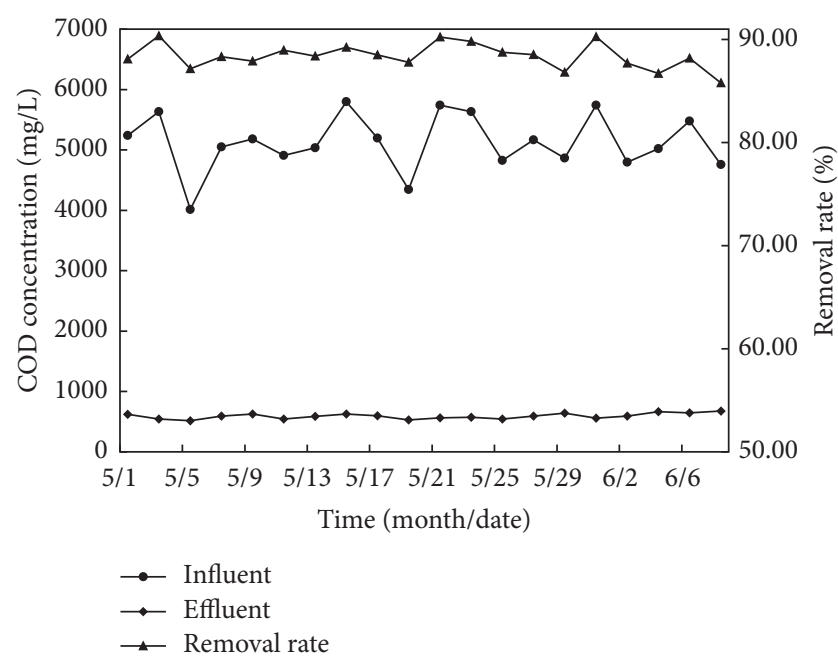

FIGURE 3: COD removal from the reactor.

\section{Results and Discussion}

3.1. HCHO Removal Performance of the Reactor. Figure 2 shows the formaldehyde removal from the reactor.

Figure 2 shows that influent formaldehyde concentration is $635-1164 \mathrm{mg} / \mathrm{L}$, and the effluent formaldehyde concentration in secondary sedimentation tank is about $5 \mathrm{mg} / \mathrm{L}$. The fluctuation of influent formaldehyde concentration is large because of the complex working conditions in the field. However, the removal rate is basically stable at more than $99 \%$, with the highest at $99.5 \%$. This rate shows that the performance of the technology is ideal, and such technology can respond to the change in external conditions.

\subsection{COD Removal Performance of the Reactor. Figure 3 shows the COD removal from the reactor.}

Figure 3 shows that influent COD concentration is 4000$5800 \mathrm{mg} / \mathrm{L}$, and the effluent COD concentration in secondary sedimentation tank is $510-670 \mathrm{mg} / \mathrm{L}$. The removal rate of COD is about $89 \%$, and the highest can reach $90.36 \%$. The different removal rates of formaldehyde and COD show that formaldehyde degradation and its degradation products are not completely synchronous $[12,13]$. Longer time is needed before it becomes fully biodegradable.

The system has a total of six units of series reactor, which includes three stages of anaerobic reaction, two stages of aerobic reaction, and a hydrolysis acidification phase. This process is relatively complicated, which can be carried out in in-depth degradation processing in the view of high COD concentration and complex wastewater. Table 4 presents the quality index of polyformaldehyde wastewater.

First, high-concentration wastewater underwent three continuous anaerobic reaction systems with long anaerobic reaction time. Both the flora in graded response and the differentiation of ecological level are abundant. At this stage, most of the carbon sources that can be used are degraded by anaerobic microbes. Thus, most of the reactor formaldehyde and COD are removed during the anaerobic phase, and the removal rate reaches $62.6 \%$ and $73.3 \%$, respectively. The biochemical substance content in the effluent water at anaerobic phase is relatively small. Most of these substances are materials that are difficult to use via anaerobic microbes. The organic matter is degraded and mineralized in depth in aerobic phase. Macromolecular organic matter and intermediate metabolites are decomposed sequentially in the hydrolysis acidification phase; these materials are then translated thoroughly into harmless substance and discharged after secondary aerobic phase.

\subsection{Sludge Ecology Analysis in the Reactor}

3.3.1. Microbial Numbers and Diversity. The results of operational taxonomic unit (OTU), abundance (Chao 1), and diversity (Shannon) index of microbial community were obtained by high-through sequencing. The microbial community diversity in the sludge sample of the reactor is shown in Table 5. The Shannon index of the sediment samples changes in the range of 5.44-6.74. Shannon index is low at the three-step anaerobic, hydrolysis, and acidification stages. Such low value may be attributed to that as the reaction continues; the bacteria, which are not adapted to the environment, gradually lose activity, age, and die because of the continuous change of DO and nutrition matrix. When the hydrolysis acidification phase is reached, the sludge activity is reduced because the life cycle of anaerobic microbes is longer than those of aerobic ones, and the sludge accumulated in the bottom causes inadequate contact with wastewater and poor microbial diversity [14].

Chao 1 and OTU index had a similar change rule with Shannon index. These three indicators describe the microbial diversity and its relationship with the effect of wastewater treatment. The results also reflect that the microbial diversity is high, and the treatment effect is relatively good in the reaction pool [15].

3.3.2. Phylum Level of Community Composition in Sludge Samples. The microbial classification in sludge samples according to phylum is shown in Figure 4. Comparing with sequence in the library construction, we can determine the kinds of microbial communities. Proteobacteria, Firmicutes, 
TABLE 4: Quality index of polyformaldehyde wastewater.

\begin{tabular}{|c|c|c|c|c|c|c|c|c|}
\hline & Raw water & $\begin{array}{l}\text { Effluent water of iron } \\
\text { and carbon } \\
\text { microelectrolysis }\end{array}$ & $\mathrm{A} 1$ & $\mathrm{~A} 2$ & A3 & $\mathrm{O} 1$ & Hydrolytic acidification & $\mathrm{O} 2$ \\
\hline $\mathrm{HCHO}(\mathrm{mg} / \mathrm{L})$ & 638 & 511 & 191 & 9.81 & - & 10.3 & 8.6 & 10.5 \\
\hline $\mathrm{COD}(\mathrm{mg} / \mathrm{L})$ & 4957.2 & 3772.2 & 1006.4 & 920.0 & 654.0 & 303.0 & 283.0 & 276.4 \\
\hline $\mathrm{pH}$ & 3.5 & 5.0 & 7.0 & 7.2 & 7.5 & 7.5 & 7.5 & 8.0 \\
\hline Temperature $\left({ }^{\circ} \mathrm{C}\right)$ & - & - & 35.0 & 36.0 & 35.0 & 35.0 & 36.0 & 31.0 \\
\hline
\end{tabular}

TABle 5: Microbial community diversity in the sludge sample of the reactor.

\begin{tabular}{lccc}
\hline Samples number & Chao 1 & Shannon index & OTU number \\
\hline A1D & 1458.35 & 6.74 & 1053 \\
A2D & 1281.31 & 6.42 & 903 \\
A3D & 1351.01 & 5.84 & 856 \\
O1D & 1815.04 & 6.65 & 1219 \\
BD & 911.64 & 5.44 & 663 \\
O2D & 1608.42 & 6.14 & 991 \\
\hline
\end{tabular}

Bacteroidetes, Actinobacteria, Chloroflexi, Planctomycetes, and Thermotogae are the dominant bacterial communities in the samples.

Proteobacteria $(30.1 \%-67.2 \%)$ are dominant in all of the samples [16]. Proteobacteria are one of the largest bacterial categories, which belong to gram-negative bacteria. Their outer membrane is mainly composed of lipopolysaccharide. The metabolic type is different among different members, and most of them is facultative or obligate anaerobic. Proteobacteria are the main groups of bacteria in the wastewater treatment system and plays an important role in the removal of organic matter from wastewater $[17,18]$. In wastewater treatment process, the amount of Proteobacteria decreases from $67.2 \%$ to $30.1 \%$ of hydrolysis acidification phase and subsequently increases to $52.1 \%$. This result might be because Firmicutes and Bacteroidetes begin to multiply and occupy some ecological niches of Proteobacteria [19] through anaerobic fermentation.

Firmicutes is gram-positive bacteria. The peptidoglycan content accounts for $50 \%-80 \%$ of the total quality of cell walls. Firmicutes is absolutely dominant in hydrolysis acidification phase $[20,21]$. Its proportion gradually increases from $9.8 \%$ to $37.1 \%$ of hydrolysis acidification phase in the reactor.

Bacteroidetes is autotrophic bacteria that can translate macromolecular organic matter (protein, starch, and lipid) into small molecules through hydrolysis and fermentation. Bacteroidetes includes some nitrogen-fixing bacteria, which play a part in the denitrification process $[22,23]$.

\subsubsection{Family and Genus Levels of Community Composition} in Sludge Samples. The microbial classification in sludge samples according to family and genus is shown in Figure 5. The distribution of family and genus levels can reflect detailed

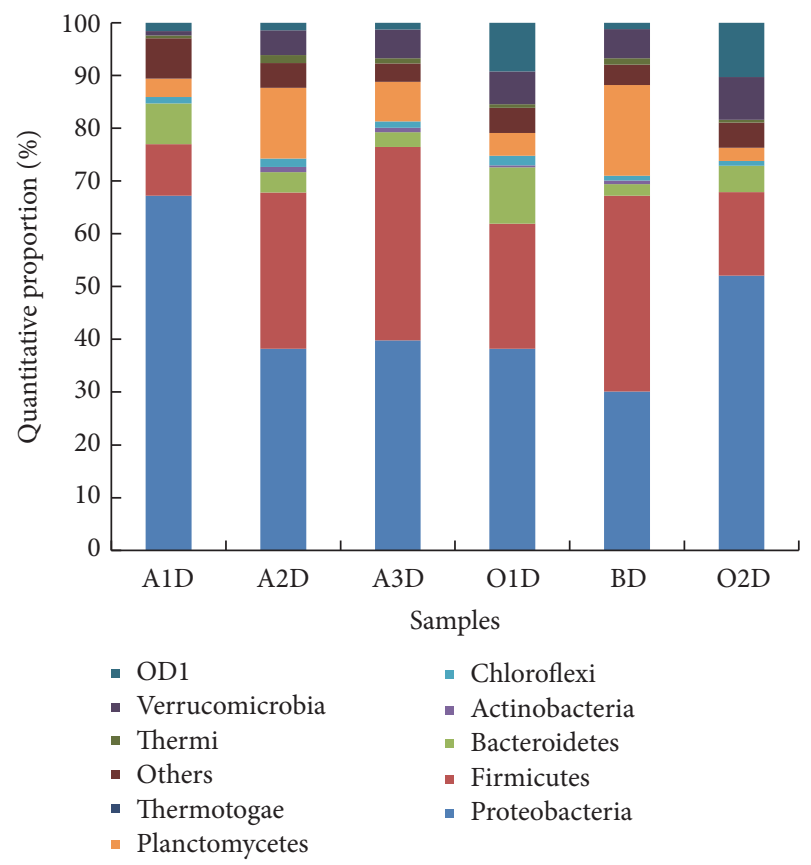

Figure 4: Classification of microbes in sludge samples according to phylum.

microbial functional information in the system. Microbial community has certain similarity in the same system. The dominant microflora slightly changes and has certain regularity. Peptostreptococcaceae (3.3\%-27.2\%), Phycisphaerales $(0.9 \%-14.2 \%)$, Rhodobacteraceae $(5.0 \%-15.2 \%)$, Azospirillum (2.1\%-11.9\%), Rhodocyclaceae (0.6\%-8.8\%), Alphaproteobacteria_BD7-3 (0.2\%-6.2\%), Piscirickettsiaceae (0.9\%-3.5\%), and Candidatus Xiphinematobacter $(0.7 \%-$ $8.1 \%$ ) are the dominant bacterial communities in the samples. Most of these communities belong to Proteobacteria.

This process system is further complicated. Different processing units have different functions in the system. The anaerobic phase is relatively different between aerobic phases. Microbial communities in different units show typical representative characteristic affected with working conditions and influent concentration.

Rhodobacteraceae is the dominant microbes in the onestep anaerobic process. These bacteria can accumulate phosphorus in denitrification [24-26]. Rhodobacteraceae and Rhodocyclaceae play an important role in organic matter 


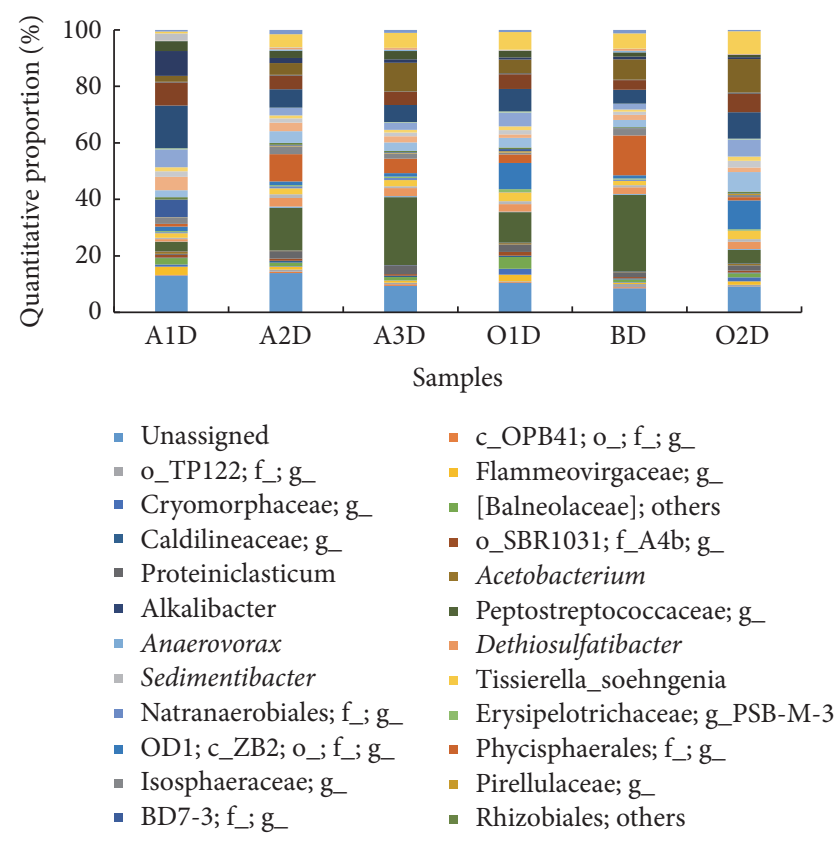

FIGURE 5: Microbial classification in the sludge samples according to family and genus.

degradation [27]. Approximately $60 \%$ of the formaldehyde is decomposed during the one-step anaerobic process (Figure 4). Both the numbers of Rhodobacteraceae and Rhodocyclaceae obviously decline with formaldehyde degradation. Therefore, Rhodobacteraceae and Rhodocyclaceae should be the main formaldehyde degradation bacteria in the reactor.

Most of formaldehyde and COD have been degraded in the one-step anaerobic process, and thus two- and threestep anaerobic processes are the main procedures of in-depth anaerobic treatment. The microbial community structures of these two processes are relatively similar, and Peptostreptococcaceae and Phycisphaerales are the dominant bacteria in the system. Phycisphaerales belongs to Planctomycetes and is the anaerobic ammonia oxidation bacterium. These bacteria can create nitrite-oxidizing ammonium and produce nitrogen under anoxic conditions, which contribute to denitrification $[28,29]$.

After entering the aerobic reaction stage, the diversity of microbial community structure increases in the reactor because the bacterial aerobic metabolism grows quickly, including the increase of nitrifying bacteria, which has high DO demand.

Peptostreptococcaceae is the dominant microbes during hydrolysis acidification. This microbe belongs to Firmicutes and typically uses little or no sugar. It can decompose protein to produce acetic acid [19]. Peptostreptococcaceae reaches about $27.2 \%$ in this process, which illustrates that it has already reached the vigorous stage of acid production. Peptostreptococcaceae is also distributed at all stages in the system and has an obvious advantage in the middle of four stages. This microbe is a facultative aerobic bacterium and plays an important role in the removal of organic matter, specifically the acidification decomposition of middle metabolites.
In addition, Azospirillum is distributed at all stages in the system; these nitrogen-fixing microbes belong to Proteobacteria and can fix nitrogen with cereals and Gramineae [30]. Azospirillum is also part of the denitrifying bacteria groups and can translate nitrate into $\mathrm{N}_{2} \mathrm{O}$ or $\mathrm{N}_{2}$ under enzyme catalysis. This microbe also has a role in the nitrogen cycle [31].

Candidatus Xiphinematobacter grows with the reaction and belongs to Thermotogae. This microbe is a kind of nitrifying bacteria, and little information is available regarding it.

\subsubsection{RDA (Redundancy Analysis) of Dominant Bacterium} in Sludge Samples. Figure 6 shows the RDA of dominant bacterium and major environmental factor in sludge samples. Rhodobacteraceae and Rhodocyclaceae have a high correlation with formaldehyde removal rate, which is consistent with the conclusions mentioned above.

Piscirickettsiaceae and Alphaproteobacteria_BD7-3 also have a high correlation with COD removal rate. Piscirickettsiaceae belongs to $\gamma$-Proteobacteria and uses organic matter as the main carbon source. It also plays an important role in COD removal process [28]. Alphaproteobacteria_BD7-3 belongs to $\alpha$-Proteobacteria and has not been named. Most of $\alpha$-Proteobacteria is saprophytic heterotrophic bacteria, and their main carbon source is the organic matter. Therefore, these bacteria are important in the removal process of COD [30].

\section{Conclusions}

(1) Multistage A-O-activated sludge process has good treatment effect on polyformaldehyde wastewater. Under the initial formaldehyde concentration of $635-1164 \mathrm{mg} / \mathrm{L}$ and COD concentration of $4000-5800 \mathrm{mg} / \mathrm{L}$, the removal rates of formaldehyde are basically stable at more than $99 \%$ and those of COD are about $89 \%$. This method can remove pollutant effectively. We hoped that our work can provide certain technical support for the actual project.

(2) The ecology of activated sludge in different reaction stages through high-throughput sequencing was analyzed. The analysis results of microbial diversity indices (Shannon, Chao 1, and OTU) indicated that the microbial diversity of the reactor is high, and the treatment effect is good. Microbial community has certain similarity in the same system. Microbial communities in different units show typical representative characteristic affected with working conditions and influent concentration.

(3) The microbial community structure of the sludge samples was also analyzed. Proteobacteria, Firmicutes, and Bacteroidetes are dominant fungal genera in the phylum level of community composition. Peptostreptococcaceae, Phycisphaerales, and Rhodobacteraceae are dominant fungal genera in the family and genus levels of community composition. Peptostreptococcaceae is distributed at various stages and dominant in this system. This bacterium also plays an important role in organic matter removal, particularly the decomposition in middle metabolite acidification. Rhodobacteraceae and Rhodocyclaceae are formaldehydedegrading bacteria in the reactor. 


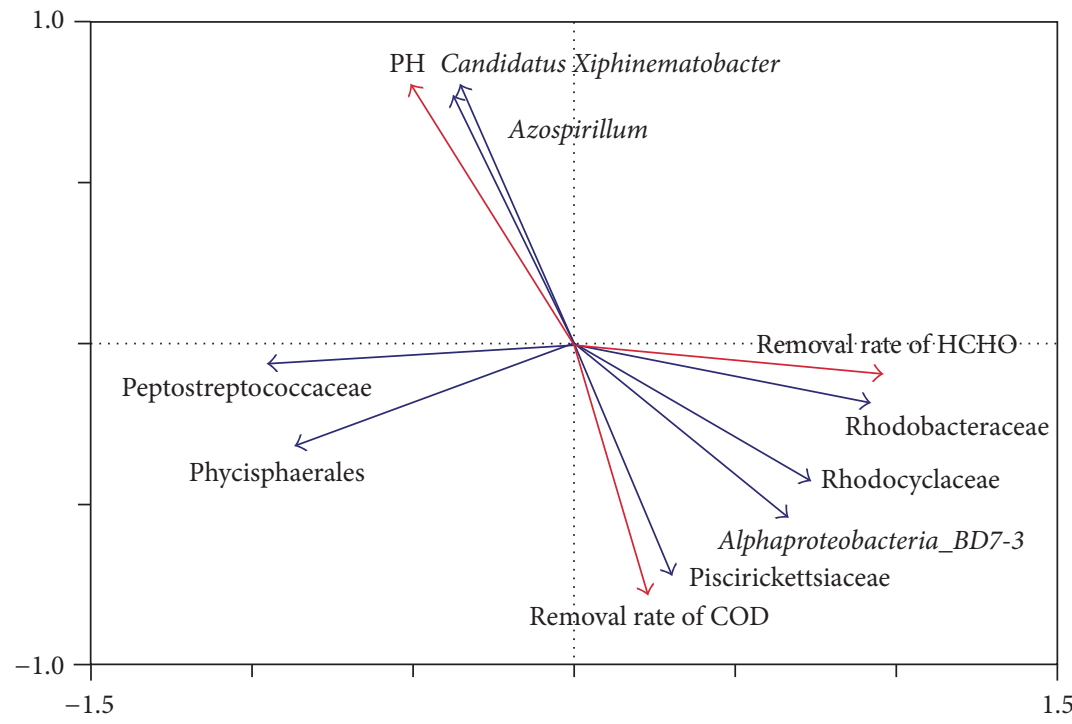

FIGURE 6: RDA of advantage bacterium in sludge samples.

\section{Competing Interests}

The authors declare that they have no competing interests.

\section{Acknowledgments}

This study was supported by the National Natural Science Foundation of China (Grants nos. 51178048 and 51378064) and the Fundamental Research Funds for the Central Universities (Grant no. 2014KJJCB22).

\section{References}

[1] Q. Cao, "Advances in formaldehyde wastewater treatment," Pollution Control Technology, vol. 22, no. 4, pp. 55-58, 2009.

[2] Z. J. Xu, Z. F. Cheng, A. J. Lin, J. G. Wang, and H. Tong, "Removal of formaldehyde from wastewater by activated sludge," Chinese Journal of Environmental Engineering, vol. 2, no. 9, pp. 1173-1176, 2008.

[3] H. X. Yang, The Study on Biodegradation of Industrial Formaldehyde Wastewater Using Sequencing Batch Reactor Processing, Nanjing University of Science \& Technology, 2013.

[4] A. Hidalgo, A. Lopategi, M. Prieto, J. L. Serra, and M. J. Llama, "Formaldehyde removal in synthetic and industrial wastewater by Rhodococcus erythropolis UPV-1," Applied Microbiology and Biotechnology, vol. 58, no. 2, pp. 260-263, 2002.

[5] Z. H. Wang, H. B. Wei, Z. Y. Jia, Y. M. Lu, X. Liu, and P. Zou, "Activated sludge process for treatment of formaldehyde wastewater," China Water \& Wastewater, vol. 25, no. 1, pp. 86-87, 2009.

[6] S. Mirdamadi, A. Rajabi, P. Khalilzadeh, D. Norozian, A. Akbarzadeh, and F. A. Mohseni, "Isolation of bacteria able to metabolize high concentrations of formaldehyde," World Journal of Microbiology and Biotechnology, vol. 21, no. 6-7, pp. 12991301, 2005.

[7] N. Kato, H. Kobayashi, M. Shimao, and C. Sakazawa, "Properties of formaldehyde dismutation catalyzing enzyme of Pseudomonas-putida F61," Agricultural and Biological Chemistry, vol. 48, no. 8, pp. 2017-2023, 1984.
[8] A. Habibi and F. Vahabzadeh, "Degradation of formaldehyde at high concentrations by phenol-adapted Ralstonia eutropha closely related to pink-pigmented facultative methylotrophs," Journal of Environmental Science and Health-Part A Toxic/Hazardous Substances and Environmental Engineering, vol. 48, no. 3, pp. 279-292, 2013.

[9] N. N. Maidan, M. V. Gonchar, and A. A. Sibirny, "Oxidation of exogenous formaldehyde in methylotrophic and nonmethylotrophic yeast cells," Biochemistry, vol. 62, no. 6, pp. 636-640, 1997.

[10] SEPA, The Editorial Committee of Water and Waste Water Monitoring and Analysis Methods, Environmental Science Press, Beijing, China, 4th edition, 2002.

[11] Y. Qu, X. Zhang, W. Shen et al., "Illumina MiSeq sequencing reveals long-term impacts of single-walled carbon nanotubes on microbial communities of wastewater treatment systems," Bioresource Technology, vol. 211, pp. 209-215, 2016.

[12] P. Kaszycki, M. Tyszka, P. Malec, and H. Kołoczek, "Formaldehyde and methanol biodegradation with the methylotrophic yeast Hansenula polymorpha. An application to real wastewater treatment," Biodegradation, vol. 12, no. 3, pp. 169-177, 2001.

[13] A. Habibi and F. Vahabzadeh, "Degradation of formaldehyde in packed-bed bioreactor by kissiris-immobilized Ralstonia eutropha," Biotechnology and Bioprocess Engineering, vol. 18, no. 3, pp. 455-464, 2013.

[14] S. Y. He, J. X. Li, Y. T. Xu, Z. T. Hu, and Y. G. Wang, “The microbial community structure of brewery wastewater treatment system by hydrolytic acidification and SBR technics," Technology of Water Treatment, vol. 34, no. 3, pp. 35-38, 2008.

[15] D. Cui, Microbial Community Analysis of Bioaugmented Biological Wastewater Treatment Systems at Low Temperature, Harbin Institute of Technology, 2014.

[16] Z. Wang, Y. Yang, Y. Dai, and S. Xie, "Anaerobic biodegradation of nonylphenol in river sediment under nitrate- or sulfatereducing conditions and associated bacterial community," Journal of Hazardous Materials, vol. 286, pp. 306-314, 2015.

[17] M. Madigan and J. Martinko, Brock Biology of Microorganisms, Prentice Hall, New York, NY, USA, 11th edition, 2005. 
[18] Y. Xu, Evolution of the Structures and Functions of the Microbial Community during Adapting to Different Wastewater Treatment Systems, Henan Normal University, Xinxiang, China, 2013.

[19] G. G. Liu, Microbial Community Succession of Excess Sludge Acidification Process Contral in Bench Scale, Harbin Institute of Technology, Harbin, China, 2015.

[20] D. Zhang, Y. Chen, Y. Zhao, and X. Zhu, "New sludge pretreatment method to improve methane production in waste activated sludge digestion," Environmental Science and Technology, vol. 44, no. 12, pp. 4802-4808, 2010.

[21] H. Zhang, J. E. Banaszak, P. Parameswaran, J. Alder, R. Krajmalnik-Brown, and B. E. Rittmann, "Focused-Pulsed sludge pre-treatment increases the bacterial diversity and relative abundance of acetoclastic methanogens in a full-scale anaerobic digester," Water Research, vol. 43, no. 18, pp. 45174526, 2009.

[22] F. Y. Shi, B. B. Song, and S. Z. Fu, "Pilot study on ammonium removal efficiency and nitrifying bacteria variety in marine biofilter charged with bamboo substrate," Progress in Fishery Sciences, vol. 3, no. 1, pp. 92-96, 2009.

[23] V. R. Hill, A. M. Kahler, N. Jothikumar, T. B. Johnson, D. Hahn, and T. L. Cromeans, "Multistate evaluation of an ultrafiltrationbased procedure for simultaneous recovery of enteric microbes in 100-liter tap water samples," Applied and Environmental Microbiology, vol. 73, no. 13, pp. 4218-4225, 2007.

[24] X. X. Jiang, Research on the Nitrogen and Phosphorous Removal Efficiency and Microbial Properties of SBR Process Operated in the Mode of A/O/A, Harbin Institute of Technology, 2011.

[25] H. Y. Wang, Y. X. Zhou, and J. Y. Jiang, "Microbial populations and community structure characterization technologies of the enhanced biological phosphate removal system," Microbiology, vol. 32, no. 1, pp. 118-122, 2005.

[26] C. J. Sun, Efficiency of Denitrifying Phosphorus Removal and Community Structure in Two Stage Biological Filters Operated by Alternative Aeration, University of Jinan, 2015.

[27] X. Hong, B. B. Liu, and X. J. Zhang, "Comparison of microbial community structure of quinoline and in dole acclimated denitrifying bioreactor," Acta Microbiologica Sinica, vol. 48, no. 4, pp. 503-507, 2008.

[28] D. Weissbrodt, S. Lochmatter, and T. R. Neu, "Isolation and physiological characteristics on strictly anaerobic hydrogen-producing bacteria (Thermopirellula anaerlimosa) of Planctomycetes," Acta Microbiologeca Sinica, vol. 52, no. 8, pp. 994-1001, 2012.

[29] C. Peng, Study on Biological Denitrification Efficiency and Microbial Diversity of Composite Iron Enzymatic Biofilm Technology, Qingdao University of Technology, Qingdao, China, 2015.

[30] P. M. Yan, H. P. Qiao, and W. J. Zhao, "Effects of methyl bromide fumigation on community structure of denitrifying bacteria with nitrousoxide reductase gene (nosZ) in soil," Acta Microbiologica Sinica, vol. 55, no. 1, pp. 73-79, 2015.

[31] Y. Y. Xu, X. H. Xu, G. M. Ren, Y. Sun, and H. T. Li, “Effect of microbial inoculum on denitrifying bacterial communities in cow manure compost," Journal of Agro-Environment Science, vol. 34, no. 3, pp. 570-577, 2015. 

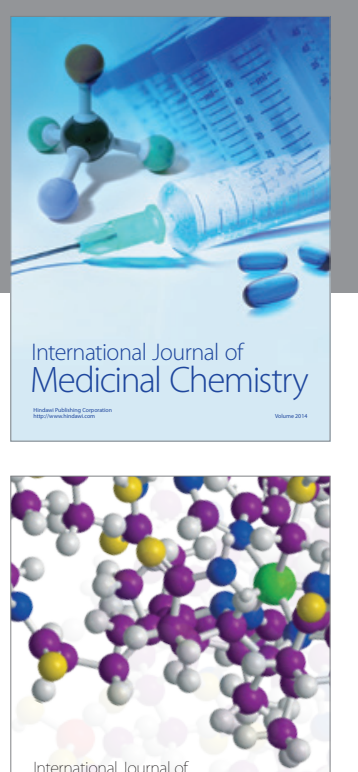

Carbohydrate Chemistry

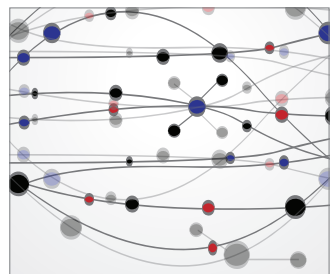

The Scientific World Journal
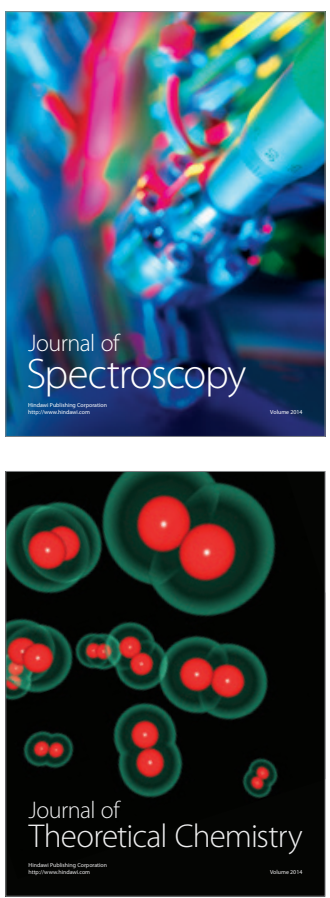
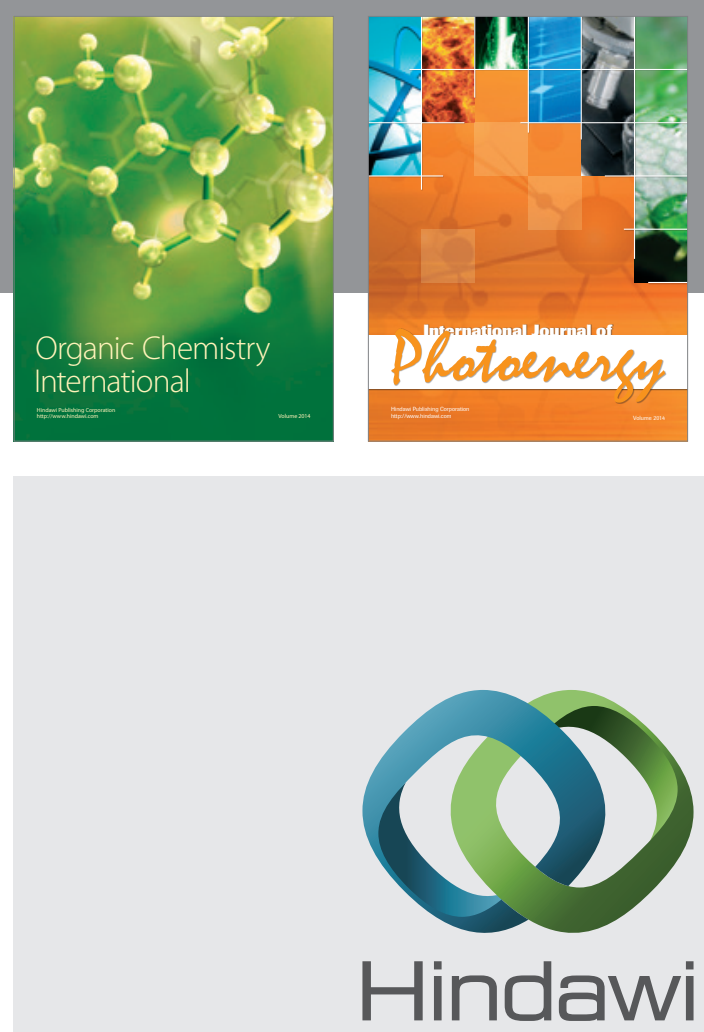

Submit your manuscripts at

http://www.hindawi.com

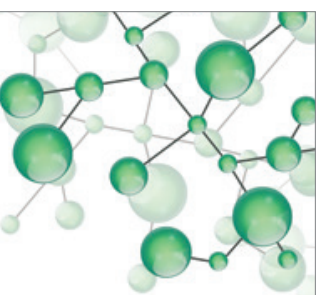

International Journal of

Inorganic Chemistry

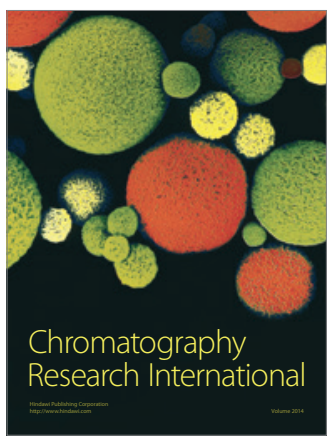

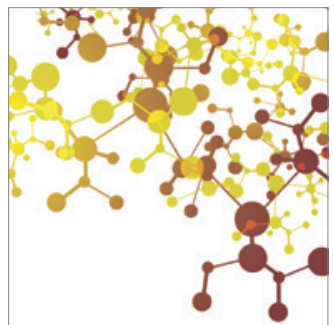

Applied Chemistry
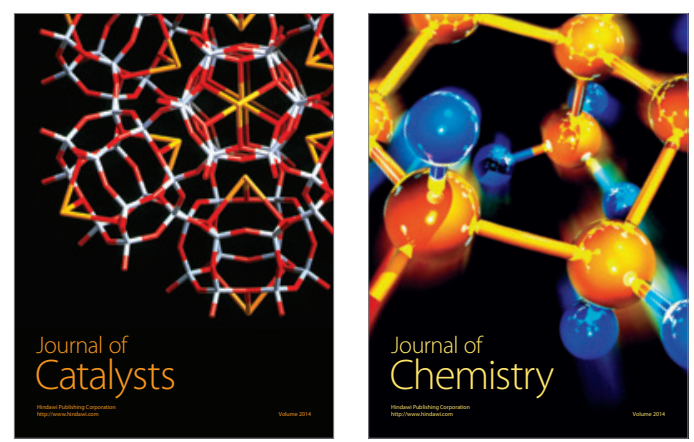
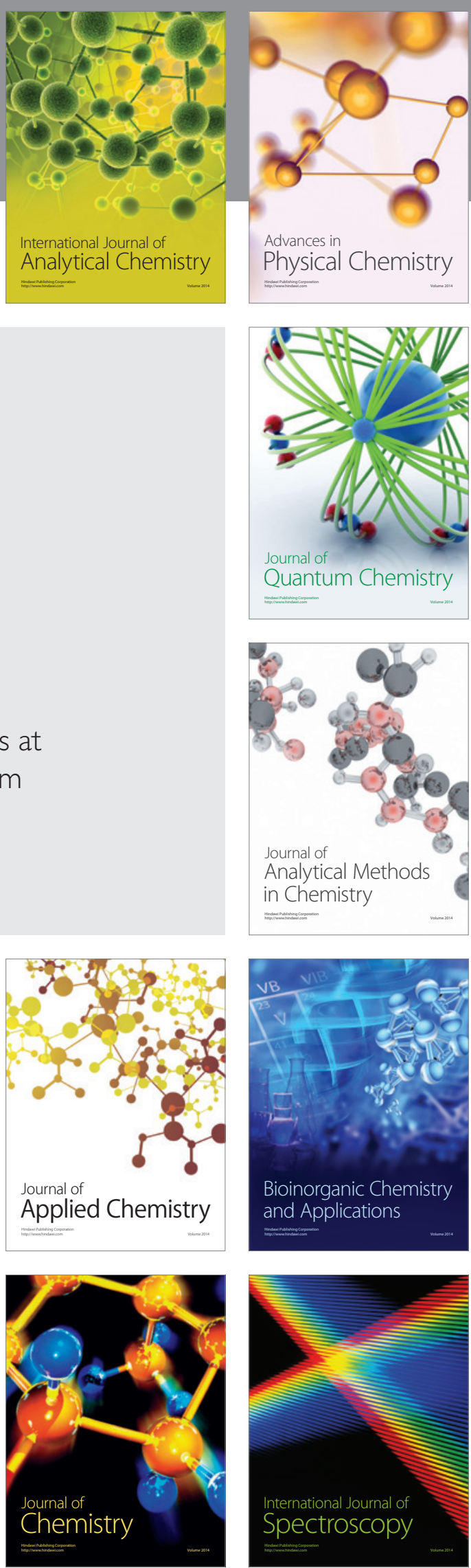